\title{
Simulations of Underground Structures Subjected to Dynamic Loading using the Distinct Element Method
}

\author{
J. P. Morris, L. A. Glenn, F. E. Heuze, M. P. Bonner
}

This article was submitted $13^{\text {th }}$ Biennial International Conference of the American Physical society on Shock Compression of Condensed Matter, Portland, OR, July 20-25, 2003

U.S. Department of Energy

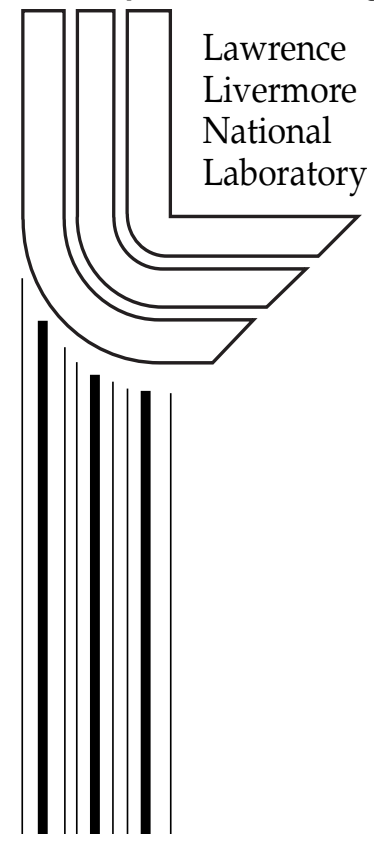




\section{DISCLAIMER}

This document was prepared as an account of work sponsored by an agency of the United States Government. Neither the United States Government nor the University of California nor any of their employees, makes any warranty, express or implied, or assumes any legal liability or responsibility for the accuracy, completeness, or usefulness of any information, apparatus, product, or process disclosed, or represents that its use would not infringe privately owned rights. Reference herein to any specific commercial product, process, or service by trade name, trademark, manufacturer, or otherwise, does not necessarily constitute or imply its endorsement, recommendation, or favoring by the United States Government or the University of California. The views and opinions of authors expressed herein do not necessarily state or reflect those of the United States Government or the University of California, and shall not be used for advertising or product endorsement purposes.

This is a preprint of a paper intended for publication in a journal or proceedings. Since changes may be made before publication, this preprint is made available with the understanding that it will not be cited or reproduced without the permission of the author.

This work was performed under the auspices of the United States Department of Energy by the University of California, Lawrence Livermore National Laboratory under contract No. W-7405-Eng-48.

This report has been reproduced directly from the best available copy.

Available electronically at http://www.doc.gov/bridge

Available for a processing fee to U.S. Department of Energy

And its contractors in paper from

U.S. Department of Energy

Office of Scientific and Technical Information

P.O. Box 62

Oak Ridge, TN 37831-0062

Telephone: (865) 576-8401

Facsimile: (865) 576-5728

E-mail: reports@adonis.osti.gov

Available for the sale to the public from

U.S. Department of Commerce

National Technical Information Service

5285 Port Royal Road

Springfield, VA 22161

Telephone: (800) 553-6847

Facsimile: (703) 605-6900

E-mail: orders@ntis.fedworld.gov

Online ordering: http://www.ntis.gov/ordering.htm

\section{OR}

Lawrence Livermore National Laboratory

Technical Information Department's Digital Library

http://www.llnl.gov/tid/Library.html 


\title{
SIMULATIONS OF UNDERGROUND STRUCTURES SUBJECTED TO DYNAMIC LOADING USING THE DISTINCT ELEMENT METHOD
}

\author{
J. P. Morris ${ }^{1}$, L. A. Glenn ${ }^{1}$, F. E. Heuze ${ }^{1}$, M. P. Bonner ${ }^{1}$ \\ ${ }^{1}$ Energy and Environment, Lawrence Livermore National Laboratory, Livermore CA 94551
}

\begin{abstract}
We present preliminary results from a parameter study investigating the stability of underground structures in response to explosion-induced strong ground motions. In practice, even the most sophisticated site characterization may lack key details regarding precise joint properties and orientations within the rock mass. Thus, in order to place bounds upon the predicted behavior of a given facility, an extensive series of simulations representing different realizations may be required. The influence of both construction parameters (reinforcement, rock bolts,liners) and geological parameters (joint stiffness, joint spacing and orientation, and tunnel diameter to block size ratio) must be considered. We will discuss the distinct element method (DEM) with particular emphasis on techniques for achieving improved computational efficiency, including the handling of contact detection and approaches to parallelization. We also outline the continuum approaches we employ to obtain boundary conditions for the distinct element simulations. Finally, our DEM code is used to simulate dynamic loading of a generic subterranean facility in hardrock, demonstrating the suitability of the DEM for this application.
\end{abstract}

\section{INTRODUCTION}

This paper summarizes a, methodology for prediction of damage to an underground structure due to explosive loading. To predict damage sustained by underground structures, several coupled regions must be modeled (set Figure 1). In the immediate vicinity of an explosion, the ground shock is sufficient to rubblize the rock, material strength is irrelevant, and the material behavior is hydrodynamic. Further from the explosion, material strength becomes important. Finally, in the vicinity of the facility, the detailed structure of the rock mass and the excavation itself are important.

Traditionally a rock mass is deemed to fail when the strength of the material is exceeded. Failed rock is no longer able to withstand load without undergoing inelastic strains. However, hard rock strength increases markedly with increased pressure and yet it has been observed that functional damage or even complete tunnel collapse can occur at stress levels far below those previously thought to be required. For example, Figure 2 shows the collapse of an excavation in tuff subjected to loads significantly lower than the compressive strength of the rock. In this example, the discrete nature of the rock mass is evident and failure has occurred through block displacement.

Clearly, the orientation, spacing, and shear strength of geologic discontinuities such as joints and fractures can control the behavior of a tunnel. Moreover, under shear loading, hard rock joints may dilate strongly before reaching peak strength, after which the strength can drop rapidly with increased loading (Goodman 1980). As a result of the controlling effects of the joints it is not possible 


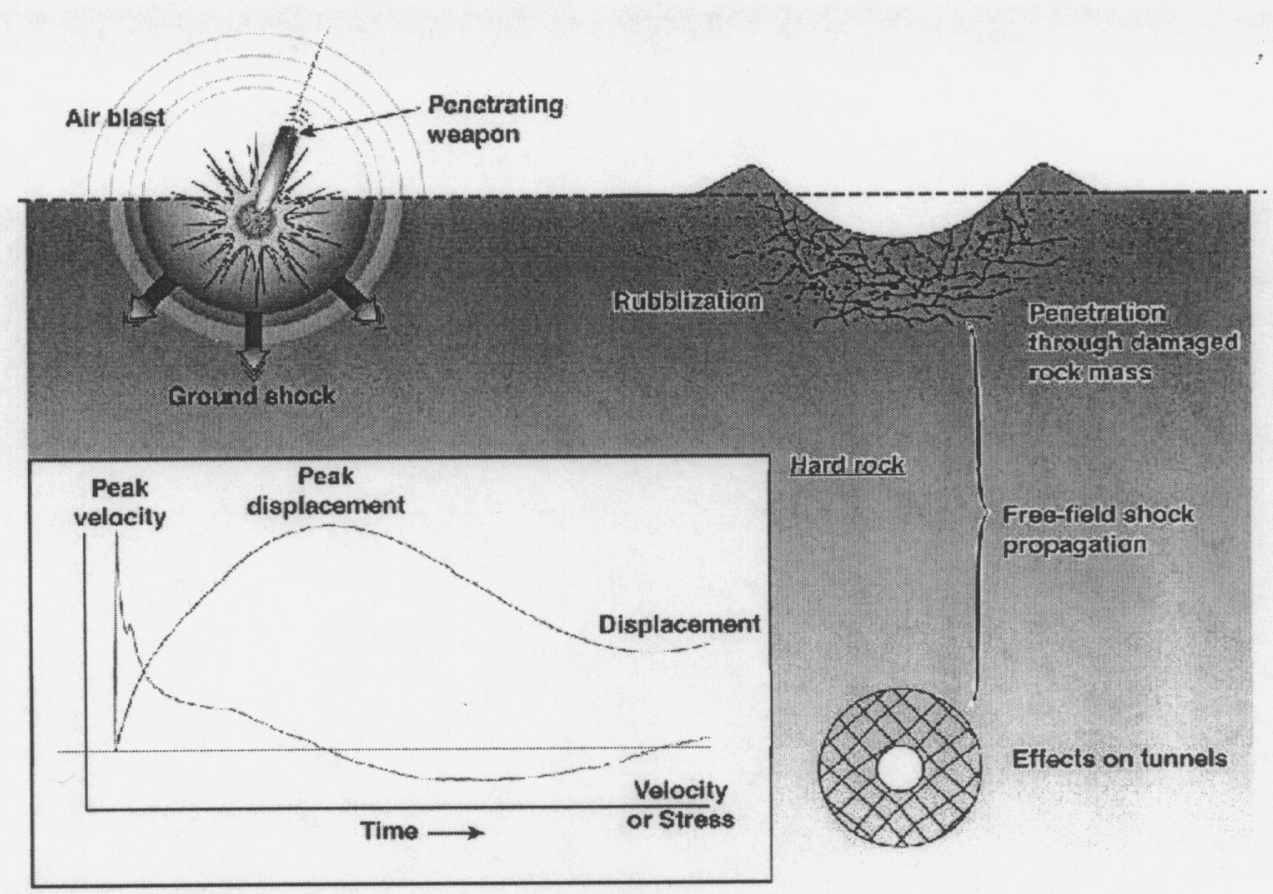

Figure 1. To predict damage inflicted upon hard and deeply buried targets, several coupled regions must be modeled.

to estimate tunnel response via continuum based analysis alone.

By nature, the Distinct Element Method (DEM) can readily handle large deformation on joints and fractures and the Lagrangian nature of the DEM simplifies tracking of material properties as blocks of material move. It is also possible to guarantee exact conservation of linear and angular momentum. The joint models can be very flexible and can incorporate experimentally observed effects such as, cohesion, joint dilation, friction angle, and hysteresis (Heuze et al. 1993).

The DEM has been applied to a wide range of problems in geomechanics. For example, Antonellini and Pollard (1995) simulated the formation of shear bands in sandstone using the DEM. Morgan (1999a,1999b) applied the DEM to the mechanics of granular shear zones. Heuze et al. (1993) used the DEM to analyze explosions in hard rock. Cundall (2001) reviews the application of the $\mathrm{DEM}$ to simulation of granular material and rock.

\section{OUR DEM IMPLEMENTATION}

We have developed a DEM capability called the Livermore Distinct Element Code (LDEC) (Morris et al, 2003). We employ the DEM as defined by Cundall and Hart (1992). In particular, the "Common-Plane" approach (Cundall, 1988) is used to reduce the complexity of the contact detection algorithm. The iterative procedure of the common- plane approach is easy to implement and is very efficient for many classes of problem. This is because the common-plane orientation from any given time-step typically provides a good initial guess of the orientation for the following time-step. Provided the normal of the contact has not changed much between time steps, the iterative procedure converges rapidly. In addition, the method detects all new contacts between blocks resulting from relative block motion.

The number of distinct elements used in a single simulation is limited by the available computational power (both processor speed and available memory). For large problems involving hundreds of thousands or millions of blocks, parallelization can be used to increase computational speed and efficiency. We chose to use an approach similar to Cleary and Sawley (1999) and parallelized the DEM through spatial domain decomposition. The entire problem domain is divided into nearest neighbor cells which are used to identify neighboring blocks which have potential contacts. Each processor is assigned a contiguous region of nearest neighbor cells. Communication occurs via message passing (MPI) at the start of each time step. All blocks within neighboring cells are copied between processors. To reduce the amount of time used for communication, each processor performs calculations on blocks that do not directly interact with neighboring processors while communication occurs. Duplicate calculations are performed on 
each processor in the region of overlap where blocks are copied back and forth. Consequently, speedup is best for larger problems where the region of overlap between processors is a smaller fraction of the total work performed.

Most commonly, deformation within the individual blocks is introduced into DEM formulations by using additional standard continuum discretization within the blocks. For example, finite elements or finite differences can be used to allow the blocks to deform (Cundall, 1980). With LDEC, the blocks are modeled using the theory of a Cosserat point (Morris et al., 2003). Using this approach the kinematics of the present deformed configuration of the block are characterized by the position vector of the block's center of mass and a triad of three deformable director vectors.

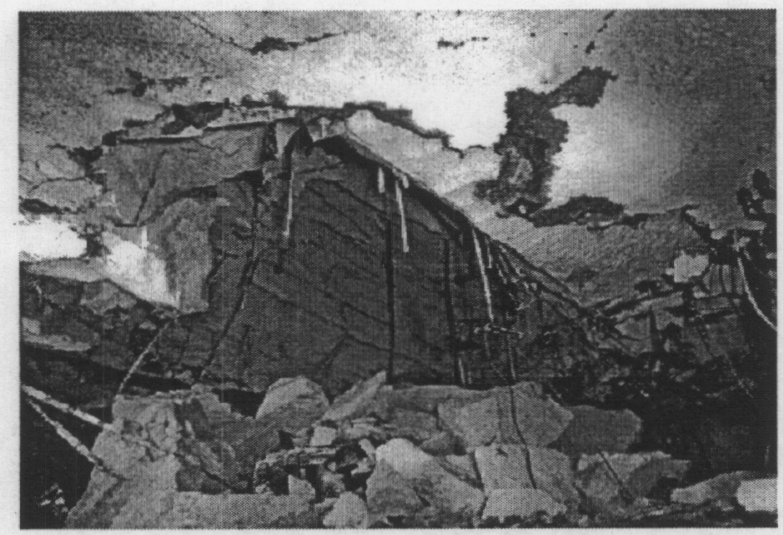

Figure 2. An excavation, reinforced with rockbolts within tuff, collapsed at low stress.

\section{SIMULATIONS OF UNDERGROUND STRUCTURES}

Our approach to simulation of excavation damage due to ground shock is to combine continuum and discrete numerical methods by applying each in different regions of the problem as discussed above and illustrated in Figure 1. Typically, the depth of the tunnel is large compared with the size of the blocks making up the rock, and continuum approaches can be used to provide boundary conditions for the DEM simulations.
Lomov et al. (2001) present an approach for accurately modeling projectile penetration and explosions in rock media. Using an Eulerian code (GEODYN) Lomov et al. (2001) fit a constitutive model (Rubin et al. 2000) to peak velocity and displacement attenuation data from tamped (buried) nuclear explosions in hard rock. This continuum treatment was able to reproduce the observed data to within a factor of two over ten orders of magnitude in yield.

The velocity or stress history predicted by GEODYN at a given point can be used to provide boundary conditions for a DEM simulation of the response of an underground facility. For our simulation the generic underground structure illustrated in Figure 3 was embedded within a jointed rock mass under $7.5 \mathrm{MPa}$ confining stress. The joint structure included three non-orthogonal joint planes. The typical block size was $50 \mathrm{~cm}$ resulting in more than 60,000 blocks in the calculation. A pulse of approximately 0.2 kbar was applied to the top of the rock island containing the structure. Figure 4 presents results from the simulation from two different viewpoints. Figure 4 shows a view into the basement rooms of the facility at times of 0 and $0.6 \mathrm{~s}$ after the arrival of the loading pulse. This figure shows that the simulation predicts extensive roof collapse in the basement.

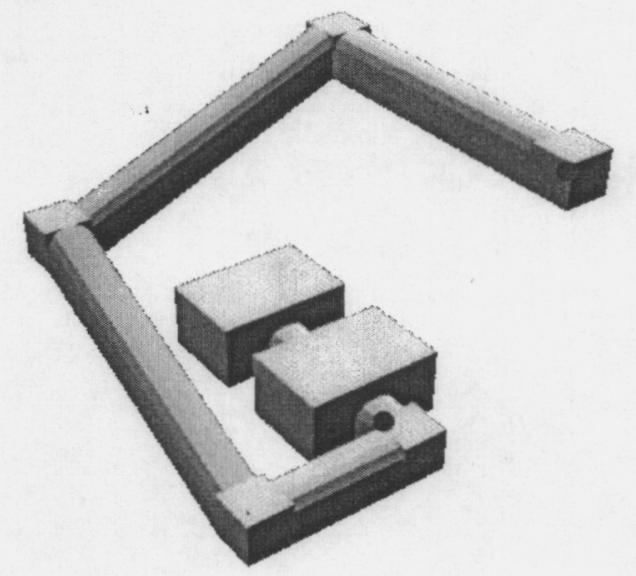

FIGURE 3. A generic underground facility with viewpoints in basement and entrance tunnel indicated. 

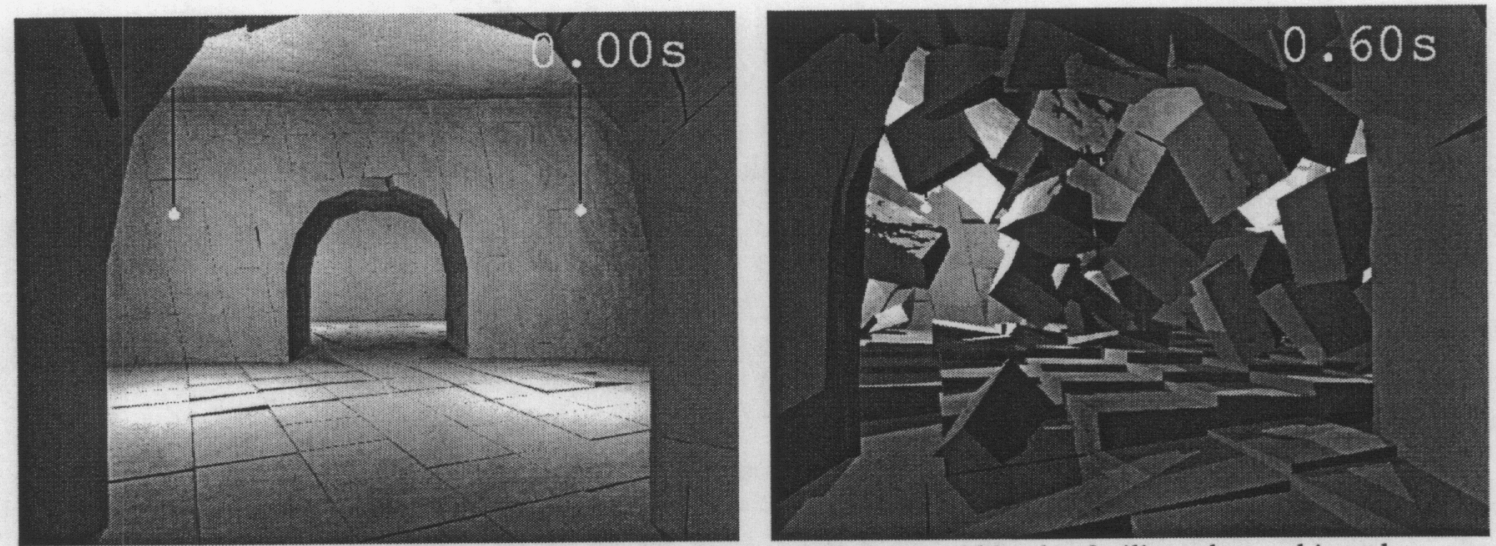

Figure 4. Simulation results indicate extensive damage to the "basement" room within the facility when subjected to a peak stress of approximately $0.2 \mathrm{kbar}$.
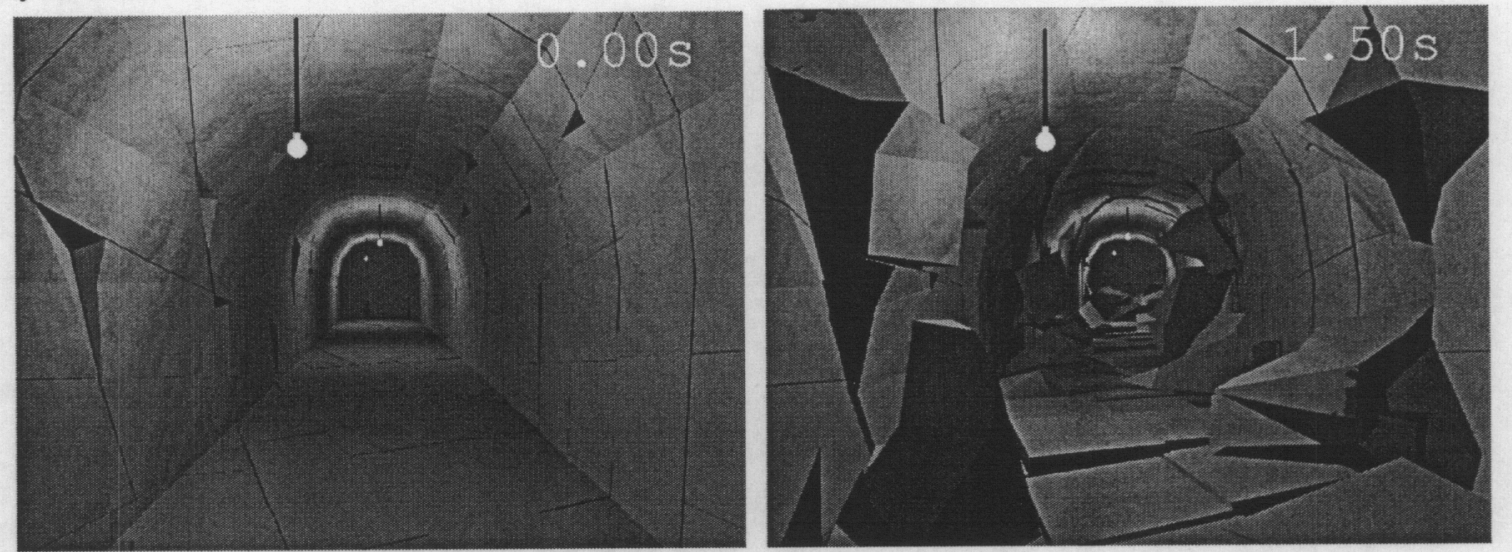

Figure 5. Simulation results indicate minimal damage to the entrance tunnel.

Figure 5 shows the entrance tunnel at times of 0.0 and $1.5 \mathrm{~s}$ after the arrival of the pulse, and indicates that the entrance tunnel remains intact with some blocks scattered along the floor. This is consistent with a narrower, arched tunnel being more stable than a larger, flat roofed opening.

\section{DISCUSSION}

These results indicate that the DEM can provide estimates of excavation damage due to explosive loading that closely resemble damage observed in field tests. In practice, however, only limited knowledge of local fault zones may be available. To provide bounds on the response, one must study a range of probable fault geometries. That is, a stochastic analysis with many realizations is required to obtain adequate statistics to bound results. Current work will include parameter studies to investigate the range of tunnel responses for given variability of joint properties.

\section{ACKNOWLEDGEMENTS}

This work was performed under the auspices of the U.S. Department of Energy by the University of California, Lawrence Livermore National Laboratory under Contract No. W-7405-Eng-48.

\section{REFERENCES}

1. Antonellini, M. A. and Pollard, D. D. (1995). "Distinct element modeling of deformation bands in sandstone." J. Struct. Geol., 17, 1165-1182. 
2. Cleary, P. W. and Sawley, M. L. (1999). "Threedimensional modelling of industrial granular flows." Second International Conference on CFD in the Minerals and Process Industries, CSIRO, Melbourne, Australia. 95-100.

3. Cundall, P. (1988). "Formulation of a threedimensional distinct element model- Part I. a scheme to detect and represent contacts in a system composed of many polyhedral blocks." Int. J. Rock Mech. Min. Sci. \& Geomech. Abstr., 25, 107-116.

4. Cundall, P. A. (2001). "A discontinuous future for numerical modelling in geomechanics?." Proc. Inst. Civ. Eng - Geotech. Eng., 149(1), 41-47.

5. Cundall, P. A. and Hart, D. H. (1992). "Numerical modelling of discontinua." Eng. Comput., 9, 101113.

6. Goodman, R.E. 1980. Introduction to Rock Mechanics. New York, New York: John Wiley \& Sons.

7. Heuzé, F. E.,Walton, O. R., Maddix, D. M., Shaffer, R. J., and Butkovich, T. R. (1993). "Analysis of explosions in hard rocks: The power of discrete element modeling." Comprehensive Rock Engineering, Vol. 2, Analysis and Design Methods, J. A. Hudson, E. T. Brown, C. Fairhurst, and E. Hoek, eds., Pergamon Press. 387-413.

8. Lomov, I., Antoun, T., and Glenn, L. (2001). "Explosion in the granite field: Hardening and softening behavior in rocks." Proceedings of 12th APS Topical Conference, Shock Compression of Condensed Matter, Atlanta, Georgia.

9. Morgan, J. K. (1999a). "Numerical simulations of granular shear zones using the distinct element method 1. Shear zone kinematics and the micromechanics of localization." J. Geophys. Res., 104(B2), 2703-2719.

10. Morgan, J. K. (1999b). "Numerical simulations of granular shear zones using the distinct element method 2. Effects of particle size distribution and interparticle friction on mechanical behavior." J. Geophys. Res., 104(B2), 2721-2732.

11. Morris, J. P., Rubin, M. B., Blair, S. C., Glenn, L A., Heuze, F. E., "Simulations of Underground Structures Subjected to Dynamic Loading using the Distinct Element Method," accepted for publication in Engineering Computations, 2003.

12. Rubin, M. B., Vorobiev, O. Y., and Glenn, L. A (2000). "Mechanical and numerical modeling of a porous elastic-viscoplastic material with tensile failure." International Journal of Solids and Structures, 37, 1841-1871. 